medRxiv preprint doi: https://doi.org/10.1101/2020.04.17.20069229; this version posted April 22, 2020. The copyright holder for this preprint (which was not certified by peer review) is the author/funder, who has granted medRxiv a license to display the preprint in perpetuity. It is made available under a CC-BY-NC-ND 4.0 International license .

\title{
Polygenic risk, susceptibility genes, and breast cancer over the life course
}

\author{
Nina Mars ${ }^{1}$, Elisabeth Widén ${ }^{1}$, Sini Kerminen ${ }^{1}$, Tuomo Meretoja ${ }^{2,3}$, Matti Pirinen ${ }^{1,4,5}$, Priit Palta ${ }^{1,6}$, \\ FinnGen, Aarno Palotie ${ }^{1,7,8}$, Jaakko Kaprio ${ }^{1,5}$, Heikki Joensuu ${ }^{3,9}$, Mark Daly ${ }^{1,8}$, Samuli Ripatti1,6,8凶
}

\section{ABSTRACT}

Polygenic risk scores (PRS) for breast cancer have potential to improve risk prediction, but there is limited information on their clinical applicability. We set out to study how PRS could help in clinical decision making. Among 99,969 women in the FinnGen study with 6,879 breast cancer cases, the PRS was associated not only with breast cancer incidence but also with a range of breast cancerrelated endpoints. Women with a breast cancer PRS above the $90^{\text {th }}$ percentile had both higher breast cancer mortality (HR 2.40,95\% Cl 1.82-3.17) and higher risk for non-localized disease at diagnosis (HR 2.94, 95\% $\mathrm{Cl} 2.63-3.28$ ), compared to those with PRS $<80^{\text {th }}$ percentile. The PRS modified the breast cancer risk of two high-impact frameshift risk variants. Women with the c.1592delT variant in PALB2 (242-fold enrichment in Finland, 263 carriers) and an average PRS (20$80^{\text {th }}$ percentile) had a lifetime risk of breast cancer at $58 \%(95 \% \mathrm{Cl} 50-66 \%)$, which increased to $85 \%$ (70-100\%) with a high PRS (>90 th percentile), and decreased to $27 \%$ (15-39\%) with a low PRS ( $<20^{\text {th }}$ percentile). Similarly, for c.1100delC in CHEK2 (3.7-fold enrichment; 1,543 carriers), the respective lifetime risks were $27 \%$ (95\% Cl 25-30\%), 59\% (52-67\%), and 18\% (13-22\%). Among breast cancer cases, a PRS $>90^{\text {th }}$ percentile was associated with risk of contralateral breast cancer with HR 1.66 (95\% Cl 1.24-2.22). Finally, the PRS significantly refined the risk assessment of women with first-degree relatives diagnosed with breast cancer, i.e. the combination of high PRS $\left(>90^{\text {th }}\right.$ percentile) and a positive family-history was associated with a 2.33 -fold elevated risk $(95 \% \mathrm{Cl} 1.57$ 3.46) compared to a positive family history alone. These findings demonstrate opportunities for a comprehensive way of assessing genetic risk in the general population, in breast cancer patients, and in unaffected family members.

\footnotetext{
1) Institute for Molecular Medicine Finland, FIMM, HiLIFE, University of Helsinki, Helsinki, Finland 2) Breast Surgery Unit, Comprehensive Cancer Center, Helsinki University Hospital, Helsinki, Finland 3) University of Helsinki, Helsinki, Finland 4) Helsinki Institute for Information Technology HIIT and Department of Mathematics and Statistics, University of Helsinki, Helsinki, Finland 5) Department of Public Health, University of Helsinki, Helsinki, Finland 6) Estonian Genome Center, Institute of Genomics, University of Tartu, Tartu, Estonia 7) Psychiatric \& Neurodevelopmental Genetics Unit, Department of Psychiatry, Analytic and Translational Genetics Unit, Department of Medicine, and the Department of Neurology, Massachusetts General Hospital, Boston,

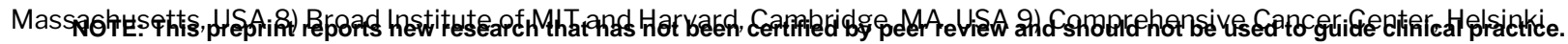
University Hospital, Helsinki, Finland
} 
medRxiv preprint doi: https://doi.org/10.1101/2020.04.17.20069229; this version posted April 22, 2020. The copyright holder for this preprint (which was not certified by peer review) is the author/funder, who has granted medRxiv a license to display the preprint in perpetuity. It is made available under a CC-BY-NC-ND 4.0 International license.

\section{INTRODUCTION}

In women, breast cancer is the most commonly diagnosed cancer and the leading cause of cancerrelated deaths. ${ }^{1}$ Approximately $5-10 \%$ of all breast cancers are estimated to develop due to highimpact germline mutations in breast cancer susceptibility genes, with up to $30 \%$ due to pathogenic mutations in BRCA1 and BRCA2 and with a smaller proportion carrying mutations in other susceptibility genes, such as PTEN, TP53, CHEK2, PALB2, and STK11. ${ }^{2}$ While pathogenic mutations in BRCA1 and BRCA2 are less common in Finns, ${ }^{3}$ two frameshift mutations, c.1592delT (rs180177102) in PALB2 and c.1100delC (rs555607708) in CHEK2 have an unusually high allele frequency in Finland, which provides a unique opportunity to explore the impact of these mutations in the population. PALB2 (Partner and Localizer of BRCA2) encodes a key tumour suppressor protein that functions through affecting BRCA2 nuclear localization and DNA damage response functions, and through interacting with BRCA1. ${ }^{4}$ The second gene, CHEK2 (Checkpoint kinase 2) is a tumour suppressor gene encoding a serine/threonine-protein kinase involved in DNA repair, cell cycle arrest, and apoptosis. ${ }^{5}$

Beyond genetic predisposition caused by high-risk variants in breast cancer susceptibility genes, breast cancer has a highly polygenic mode of inheritance. Large-scale genetic screens have to date identified over a hundred loci associated with risk of breast cancer. ${ }^{6}$ These variants, and many more yet to be discovered, represent common genetic variation acting through a wide range of molecular pathways, in contrast to the rare, high-risk pathogenic variants in high-risk breast cancer susceptibility genes that often disrupt a specific pathway involved in maintaining integrity of DNA repair processes. Individually, the common variants have very small effect sizes, but their cumulative impact in breast cancer risk has been shown to be considerable. ${ }^{7}$ This cumulative effect can be captured in a single measure by a polygenic risk score (PRS), the summed contribution of many common risk variants. ${ }^{8}$ Breast cancer PRS has been shown to improve risk stratification particularly by improving identification of individuals at high risk of breast cancer, and therefore it could potentially serve as a new tool for personalized, risk-based breast cancer screening. ${ }^{7,9}$

While previous studies have almost exclusively focused on the effect of PRS on overall risk of breast cancer, here we focus on the role of breast cancer PRS across a range of breast cancer-related endpoints and how PRS could help in clinical decision making. We therefore set out to assess three questions with high clinical relevance: 1) how does the PRS impact various breast cancer endpoints such as breast cancer mortality in the population, 2) does the PRS modify the risk of breast cancer in women carrying mutations in the PALB2 and CHEK2 genes, and 3) can the PRS inform about outcomes after breast cancer diagnosis and guide risk assessment in relatives of breast cancer patients. We explored these questions using the FinnGen study, which combines nationwide health 
medRxiv preprint doi: https://doi.org/10.1101/2020.04.17.20069229; this version posted April 22, 2020. The copyright holder for this preprint (which was not certified by peer review) is the author/funder, who has granted medRxiv a license to display the preprint in perpetuity. It is made available under a CC-BY-NC-ND 4.0 International license.

registries with genomic information and comprises 99,969 women collected across the country, representing $4 \%$ of the Finnish adult female population.

\section{METHODS}

\section{Participants and endpoints}

The data comprised of 99,969 Finnish women in the FinnGen, Data Freeze 4. FinnGen comprises prospective epidemiological cohorts (initiated as far back as 1992), disease-based cohorts, and hospital biobank samples (Supplementary Table 1). The unique national personal identification number links the genotypes to the Finnish Cancer Registry (available from 1953, with nationwide completeness of solid tumours at $96 \%{ }^{10}$ ), as well as to the national hospital discharge registry (1968-), the registry of surgical procedures (1997-), the national death registry (1969-), and the medication reimbursement registry (1995-). Endpoint definitions were the following: 1) breast cancer cases from the Cancer Registry with diagnosis C50 (International Classification of Diseases for Oncology, 3rd Edition; ICD-O-3) and from the drug reimbursement registry by selecting individuals with a reimbursement code for breast cancer (yielding an additional 856 cases, 847 of whom were diagnosed within 2 years, a delay that sometimes occurs before appearing in the cancer registry) 2) breast cancer mortality through the death registry (C50* (ICD-10) or 174* (ICD-8 and ICD9) as the underlying or contributing cause of death), 3) non-localized breast cancer at diagnosis from the Cancer Registry, by including individuals with either regional lymph node metastases, distant metastases, or non-localized disease without information on cancer extent, 4) synchronous bilateral breast cancer (from the Cancer Registry), 5) contralateral breast cancer defined as breast cancer in the opposite breast diagnosed over 6 months after the date of the primary breast cancer diagnosis (from the Cancer Registry), 6) mastectomy (procedure codes under 'HAC'), and 7) breast-conserving surgery (procedure codes under 'HAB', conditional on having breast cancer). Out of 6,879 breast cancer cases identified through the endpoint definition 1), detailed Cancer Registry information for endpoint definitions 3) to 5) was available for 6,019 breast cancer cases.

\section{Genotyping and imputation}

FinnGen samples were genotyped with Illumina and Affymetrix arrays (Illumina Inc., San Diego, and Thermo Fisher Scientific, Santa Clara, CA, USA), and genotype calls were made with the GenCall or zCall (for Illumina) and the AxiomGT1 algorithm for Affymetrix data. Individuals with ambiguous gender, high genotype missingness (>5\%), excess heterozygosity (+-4SD) and non-Finnish ancestry were excluded; as well as all variants with high missingness ( $>2 \%)$, low HWE P-value $(<1 \mathrm{e}-6)$ and minor allele count $(\mathrm{MAC}<3)$. Array data pre-phasing was carried out with Eagle 2.3.511 with the number of conditioning haplotypes set to 20,000. Genotype imputation was done with Beagle $4.1^{12}$ 
medRxiv preprint doi: https://doi.org/10.1101/2020.04.17.20069229; this version posted April 22, 2020. The copyright holder for this preprint (which was not certified by peer review) is the author/funder, who has granted medRxiv a license to display the preprint in perpetuity. It is made available under a CC-BY-NC-ND 4.0 International license.

(as described in https://dx.doi.org/10.17504/protocols.io.xbgfijw) by using the SISu v3 populationspecific reference panel developed from high-quality data for 3,775 high-coverage (25-30x) WGS in Finns.

\section{PALB2 and CHEK2 variants}

Based on a genome-wide association study (GWAS) for breast cancer within FinnGen, we chose two previously reported Finnish-enriched frameshift variants for further analyses, rs180177102 (c.1592delT) in PALB2 and rs555607708 (c.1100delC) in CHEK2. Genotype data batches with an imputation INFO score $<0.8$ were excluded. This excluded 12,599 women from analyses involving the PALB2 variant, but no exclusions were needed for CHEK2. PALB2 mutation carrier status was ignored in analyses involving the CHEK2 variant, and vice versa. Women homozygous for the CHEK2 variant were analysed jointly with the heterozygotes.

\section{Polygenic risk score}

We used a previously built and validated breast cancer PRS. ${ }^{6,13}$ In short, its input weights are from a large independent GWAS, ${ }^{6}$ and LDpred was used to account for linkage disequilibrium among loci. ${ }^{14}$ The PRS showed good calibration for overall risk of breast cancer, breast cancer mortality, and risk of non-localized breast cancer at diagnosis (Supplementary Figure 1). To create a PRS independent of the PALB2 and CHEK2 variants, we excluded the variants within the CHEK2 gene $\pm 3 \mathrm{Mb}$, and variants within the PALB2 gene $\pm 2 \mathrm{Mb}$ (Supplementary Figure 2). The final variant count for the PRS was $6,023,441$. For analysing the effect of PRS in PALB2 or CHEK2 mutation carriers, the PRS was divided into the following bins: $<20^{\text {th }}$ percentile, $20-80^{\text {th }}$ percentiles (reference category), $80-90^{\text {th }}$ percentiles, and $>90^{\text {th }}$ percentile. We chose a threshold at the $90^{\text {th }}$ percentile because it corresponds to a lifetime risk of $\geq 30 \%$, which guidelines consider as the threshold for high risk. ${ }^{15}$

\section{Geographic variation}

Geographic variation is reported by region of birth (obtained from Statistics Finland) as the proportion of individuals with 1) mutations in the PALB2 or CHEK2 variants, and 2) high PRS (>90 th percentile). Polygon data for the Finnish map were obtained from GADM (https://gadm.org/data.html).

A population structure-related bias analysis was performed by following the approach described in detail in Kerminen et al. $^{16}$ In brief, the method measures the accumulation of PRS differences between the Western and Eastern subpopulations of Finland using a "random PRS", made from a randomly chosen set of independent $\left(r^{2}<0.1\right)$ variants with minor allele frequency $>0.05$ that are not associated with breast cancer (breast cancer GWAS $^{6}$ p-value $>0.5$ ). If such random PRS accumulated differences between the subpopulations, that could indicate a population genetic bias in effect estimates of the GWAS, rather than a real difference in genetic susceptibility of breast 
medRxiv preprint doi: https://doi.org/10.1101/2020.04.17.20069229; this version posted April 22, 2020. The copyright holder for this preprint (which was not certified by peer review) is the author/funder, who has granted medRxiv a license to display the preprint in perpetuity. It is made available under a CC-BY-NC-ND 4.0 International license .

cancer between the subpopulations. We found no evidence of such bias (Supplementary Figure 3), which indicates that any detected geographic variation in the PRS is unlikely to result from a population genetic bias.

\section{Risk assessment in first-degree relatives}

The pairs of first-degree relatives were inferred with KING v2.2.4 ${ }^{17}$ by a kinship coefficient ranging between 0.177 and 0.354 (inference based on $57 \mathrm{~K}$ variants). To analyse the impact of family history in first-degree relatives, we randomly chose one female relative for each woman with at least one first-degree relative in the dataset. If both women in the pair were breast cancer cases, we used the year of diagnosis to select the woman diagnosed later as the relative of interest. Each woman could appear only once in the group we inferred the risk for.

\section{Statistical analysis}

The GWAS for breast cancer was run using a generalized mixed model implemented in SAIGE, ${ }^{18}$ adjusting for age, batches, and the first ten principal components of ancestry. We estimated hazard ratios (HRs) and 95\% confidence intervals $(\mathrm{Cl})$ with the Cox proportional hazards model, and used Schoenfeld residuals and log-log inspection for assessing the proportional hazards assumption. We used age as the time scale, with batches and the first ten principal components as covariates. In the analyses on breast cancer cases only, follow-up started from the diagnosis, and survival over one year was required, as we were interested in assessing long-term survival. Follow-up ended at the first record of the endpoint of interest, death, or at the end of follow-up on December 31, 2018, whichever came first. All tests were two-tailed. Goodness-of-fit for the PRS was assessed with a method proposed by May \& Hosmer for a Cox proportional hazards model. ${ }^{19}$ Lifetime risk by age 80 was estimated from the adjusted survival curves, with $95 \%$ Cls obtained by normal approximation. The adjusted survival curves were plotted with the R package survminer. Statistical interaction was assessed by introducing an interaction term to the survival model, with the PRS on a continuous scale. For statistical analyses, we used R 3.6.1.

Patients and control subjects in FinnGen provided informed consent for biobank research, based on the Finnish Biobank Act. Alternatively, older research cohorts, collected prior the start of FinnGen (in August 2017), were collected based on study-specific consents and later transferred to the Finnish biobanks after approval by Valvira, the National Supervisory Authority for Welfare and Health. Recruitment protocols followed the biobank protocols approved by Valvira. The Ethics Review Board of the Hospital District of Helsinki and Uusimaa approved the FinnGen study protocol Nr HUS/990/2017.

The FinnGen project is approved by the Finnish Institute for Health and Welfare (THL), approval number THL/2031/6.02.00/2017, amendments THL/1101/5.05.00/2017, THL/341/6.02.00/2018, 
medRxiv preprint doi: https://doi.org/10.1101/2020.04.17.20069229; this version posted April 22, 2020. The copyright holder for this preprint (which was not certified by peer review) is the author/funder, who has granted medRxiv a license to display the preprint in perpetuity. It is made available under a CC-BY-NC-ND 4.0 International license.

THL/2222/6.02.00/2018, THL/283/6.02.00/2019), Digital and population data service agency VRK43431/2017-3, VRK/6909/2018-3, the Social Insurance Institution (KELA) KELA 58/522/2017, KELA 131/522/2018, KELA 70/522/2019 and Statistics Finland TK-53-1041-17.

The Biobank Access Decisions for FinnGen samples and data utilized in FinnGen Data Freeze 4 include: THL Biobank BB2017_55, BB2017_111, BB2018_19, BB_2018_34, BB_2018_67, BB2018_71, BB2019_7 Finnish Red Cross Blood Service Biobank 7.12.2017, Helsinki Biobank HUS/359/2017, Auria Biobank AB17-5154, Biobank Borealis of Northern Finland_2017_1013, Biobank of Eastern Finland 1186/2018, Finnish Clinical Biobank Tampere MH0004, Central Finland Biobank 1-2017, and Terveystalo Biobank STB 2018001. Analyses of potential geographic bias of PRS were done with THL biobank permission BB2019_44.

\section{RESULTS}

We studied 99,969 women in FinnGen, with the mean age at the end of follow-up 58.5 (inter-quartile range, IQR 45.3-71.8, range 16.0 to 105.7). In FinnGen, 6,879 (6.9\%) women have been diagnosed with breast cancer, with mean age at disease onset of 58.7 (IQR 50.6-66.4, range 21.3 to 98.3 years). We first tested for genome-wide association between breast cancer diagnosis and 16,962,023 million genetic variants (Supplementary Table 2). There were 17 associated loci, including associations for the well-known frameshift variants rs180177102 in PALB2 and rs555607708 in CHEK2. The allele frequency for rs180177102 (PALB2) was 0.0014 (242-fold enrichment compared to non-Finnish non-Estonian Europeans, NFEE ${ }^{20}$ ), with 263 heterozygote mutation carriers included in the analyses. The allele frequency for rs555607708 (CHEK2) was 0.0073 (3.7 times enriched in Finns compared to NFEE), with 1,534 heterozygotes and 9 homozygote individuals in the dataset.

To characterize the impact of the two frameshift variants on the population level, we first explored the geographic distribution in their carrier status. Both the PALB2 and CHEK2 mutations had more carriers in Eastern Finland. The allele frequency ranged from close to 0 in Western Finland, to 3.1\% for CHEK2 in South Karelia and 0.8\% for PALB2 in North Karelia (Figure 1). This was in contrast with both higher breast cancer incidence and higher PRS observed in Western and Southern Finland.

\section{Effect of high-impact variants and polygenic risk in the population}

Both variants conferred considerably elevated risk for breast cancer (Table 1; detailed counts in Supplementary Table 3). The PALB2 variant conferred a risk increase for breast cancer with a hazard ratio $(\mathrm{HR})$ of $4.80\left(95 \% \mathrm{Cl} 3.72-6.18, \mathrm{p}=1.08 \times 10^{-33}\right)$, corresponding to a lifetime risk by age 80 of 58.1\% (95\% CI 52.1-64.1\%). The CHEK2 variant conferred a risk increase for breast cancer with HR $\left.2.12(95 \% \mathrm{Cl} 1.84-2.44), p=1.33 \times 10^{-26}\right)$, corresponding to a lifetime risk of $31.8 \%(95 \% \mathrm{Cl}$ 
medRxiv preprint doi: https://doi.org/10.1101/2020.04.17.20069229; this version posted April 22, 2020. The copyright holder for this preprint (which was not certified by peer review) is the author/funder, who has granted medRxiv a license to display the preprint in perpetuity. It is made available under a CC-BY-NC-ND 4.0 International license.

29.5-34.1\%). We also identified 92 carriers of five pathogenic BRCA1/BRCA2 variants (Supplementary Table 4) with a 75.1\% (95\% Cl 63.9-86.3\%) lifetime risk of breast cancer, but due to the small number of carriers we did not study these variants further. We then compared the risk of elevated PRS to the carriers of CHEK2 and PALB2 mutations (Table 1). Women with PRS above the $90^{\text {th }}$ percentile had a similar lifetime risk (31.8\%, 95\% $\left.\mathrm{Cl} 30.9-32.7 \%\right)$ as did CHEK2 mutation carriers, but a high PRS affected a nearly seven-fold larger group of women.

Of the 6,879 women diagnosed with breast cancer, $31.8 \%$ had non-localized breast cancer at diagnosis and $4.6 \%$ died of breast cancer by the end of follow-up. Synchronous bilateral breast cancer was diagnosed in $1.6 \%$ and contralateral breast cancer in 3.9\%. The breast cancer PRS was associated with all of these endpoints in the population (Table 1). Compared to individuals with PRS $<80^{\text {th }}$ percentile, in women with a PRS between the $80^{\text {th }}$ and $90^{\text {th }}$ percentiles the effect size for an association with non-localized breast cancer at diagnosis was HR 1.90 (95\% Cl 1.67-2.17, p = $2.65 \times$ $\left.10^{-22}\right)$, and in the PRS category $>90^{\text {th }}$ percentile, HR $2.94\left(95 \% \mathrm{Cl} 2.63-3.28, \mathrm{p}=1.17 \times 10^{-81}\right)$. Similarly, we observed a strong association with both bilateral breast cancer (PRS 80-90\% HR 2.08, 95\% Cl 1.15-3.76, $\mathrm{p}=0.02$; PRS >90\% HR $4.31\left(95 \% \mathrm{Cl} 2.73-6.79, \mathrm{p}=3.14 \times 10^{-10}\right)$ and with contralateral breast cancer (PRS 80-90\% HR 2.16, 95\% Cl 1.49-3.15, p = 5.61 × 10-5; PRS >90\% HR 4.41, 95\% Cl 3.30-5.89, $\left.p=1.06 \times 10^{-23}\right)$.

Next, we estimated how the PRS modifies breast cancer risk in the mutation carriers. For both PALB2 and CHEK2, a high PRS further increased the breast cancer risk. In terms of absolute lifetime risk for breast cancer by age 80 , women with the PALB2 mutation and average PRS $\left(20-80^{\text {th }}\right.$ percentile) had a lifetime risk of 58.0\% (95\% Cl 50.4-65.6\%) which increased to 84.9\% (69.999.9\%) among women with a high PRS (>90 th percentile)(Figure 2). Accordingly, the lifetime risk decreased to $26.9 \%$ (14.7-39.1\%) in women with a low PRS ( $<20^{\text {th }}$ percentile). Women with CHEK2 and average PRS had a lifetime risk of $27.4 \%$ (95\% Cl 24.5-30.3\%), which doubled to 59.2\% (51.7$66.7 \%)$ in women with a high PRS and decreased to $17.5 \%$ (13.0-22.0\%) in women with low PRS. We found no evidence of an interaction between the PRS and mutations for neither the PALB2 variant $(p=0.73)$ nor the CHEK2 variant $(p=0.32)$.

\section{Impact of polygenic risk after breast cancer diagnosis}

Next, we tested the association between PRS and disease outcomes after the breast cancer diagnosis. A high PRS ( $>90^{\text {th }}$ percentile) was associated with risk of contralateral breast cancer with HR 1.66 (95\% Cl 1.24-2.22, $p=0.0007)$, and the association remained similar when adjusting for clinical factors at baseline (Table 2). We found no association between high PRS and breast cancerrelated mortality after diagnosis (Table $\mathbf{2}$ ). 
medRxiv preprint doi: https://doi.org/10.1101/2020.04.17.20069229; this version posted April 22, 2020. The copyright holder for this preprint (which was not certified by peer review) is the author/funder, who has granted medRxiv a license to display the preprint in perpetuity. It is made available under a CC-BY-NC-ND 4.0 International license.

\section{Polygenic risk and breast cancer in first-degree relatives}

Lastly, we evaluated how the PRS modifies the risk conferred by a positive family history. This was done by estimating the risk of breast cancer in 9,702 parent-offspring pairs and 9,598 full siblingpairs. We compared the lifetime risks of $A$ ) individuals with a first-degree relative who has both breast cancer and a high PRS ( $>90^{\text {th }}$ percentile), and B) individuals with a first-degree relative who has breast cancer but does not have a high PRS ( $<90^{\text {th }}$ percentile) (Figure 3). For scenario $\left.A\right)$, the lifetime risk was $24.6 \%$ (95\% $\mathrm{Cl} 19.2-30.0 \%)$ compared to a lifetime risk of $18.8 \%$ (95\% $\mathrm{Cl} 16.3$ 21.3\%) in scenario B). If the PRS was known for the woman herself (i.e. the woman we estimate the risk for), the lifetime risk with $P R S>90^{\text {th }}$ percentile and a first-degree relative with breast cancer was $34.9 \%$ (27.8-42.0\%)(Figure 3).

\section{DISCUSSION}

Using large-scale biobank data combining nationwide health registry data with genomic information, we showed that a high breast cancer PRS is associated with breast cancer mortality, more advanced breast cancer at diagnosis, and other breast cancer-related endpoints in the population. We also demonstrate that over the life course, PRS strongly alters the breast cancer incidence in highimpact mutation carriers. After breast cancer diagnosis, individuals with an elevated PRS have an increased likelihood of developing contralateral breast cancer and PRS can considerably improve risk assessment among their female first-degree relatives.

These results allow us to draw several conclusions with clinical implications. First, we show that breast cancer PRS is associated with higher likelihood of non-localized breast cancer at diagnosis and with breast cancer-related mortality in the population. Previous studies have shown that PRS stratifies women for risk of breast cancer $7,9,13,21$ and our results show that this extends also to more advanced breast cancer and breast cancer-related death - this result is important when considering the role of PRS in the context of screening. Harbouring pathogenic mutations in high-risk breast cancer susceptibility genes often prompt intensified medical surveillance and consideration of preventative procedures such as risk-reducing surgery. Our results argue for the need of studies on the impact of targeted actions in women with a high PRS, who currently go undetected. Even after the diagnosis, patients with elevated PRS had a 1.7-fold elevated risk for contralateral cancer, providing additional evidence of increased breast cancer susceptibility, a finding that could warrant intensified or prolonged surveillance in breast cancer cases with elevated PRS. This finding is in line with previous observations that familial factors contribute to the risk of contralateral breast cancer. 22,23 
medRxiv preprint doi: https://doi.org/10.1101/2020.04.17.20069229; this version posted April 22, 2020. The copyright holder for this preprint (which was not certified by peer review) is the author/funder, who has granted medRxiv a license to display the preprint in perpetuity. It is made available under a CC-BY-NC-ND 4.0 International license .

Second, PRS strongly alters the risk of breast cancer in PALB2 and CHEK2 mutation carriers, substantially increasing the risk of breast cancer in women with a high PRS, and lowering the risk towards the population level in women with a low PRS. Deciding on appropriate surveillance and riskreduction strategies is a clinical challenge particularly for moderate-risk mutations such as those in CHEK $2,{ }^{27}$ and our results show that additional information provided by the PRS could help in these decisions. A combination of breast cancer PRS in the top decile and a mutation in the CHEK2 variant increased the lifetime risk to 59\% - a risk comparable to that seen in PALB2 mutation carriers whereas those with a PRS in the bottom quintile had a risk similar to the population level. That PRS modifies the risk in PALB2 and CHEK2 mutation carriers supports previous findings suggesting that common genetic variation at least partly explains the widely observed incomplete penetrance of mutations in breast cancer susceptibility genes. ${ }^{24-26}$ This variation is now measurable on an individual level with the breast cancer PRS, which captures a wide range of molecular pathways. This is likely to include genetic determinants of known breast cancer risk factors such as age at menarche or menopause. The interplay of these genetic factors and the PRS remain to be examined in future studies.

Third, the PRS improved risk assessment of first-degree relatives of women with breast cancer. Women with both family history and PRS in the top decile had a 2.3 times higher breast cancer risk compared to women with family history but a PRS below the top decile. Family history is an essential factor guiding screening strategies of family members of breast cancer patients, ${ }^{15}$ and our findings show that PRS could improve the precision of this assessment.

This is the first study to assess the life-course impact of a breast cancer PRS and its joint effect with high-impact risk variants in the two breast cancer susceptibility genes, PALB2 and CHEK2. We studied one clinically relevant pathogenic frameshift variant for each gene, leveraging their considerable enrichment in an isolated population. The lifetime risk estimates for individuals in the top decile of the PRS were comparable to CHEK2 mutation carriers - both had a lifetime risk of 32\%. Comparable lifetime risks were observed also in individuals with both CHEK2 mutation and high PRS (59\% lifetime risk) and those who are PALB2 mutation carriers (58\% lifetime risk). Based on prior studies, we expect the PRS to modify the risks similarly in BRCA1 and BRCA2 mutation carriers. ${ }^{26}$ As these genes are relevant in genetic counselling of breast cancer, PRS evaluation would fit in the current lifetime risk-based screening strategies and refine the risk estimation among mutation carriers. The geographical distribution of the PRS also closely followed the distribution of the breast cancer incidence, unlike the geographical distribution of the high-impact variants. The high-impact variants were more common in a late-settlement region, which has passed an internal genetic bottleneck. ${ }^{28}$ How these differences impact any potential regional genomic-based screening strategies warrants further study. 
medRxiv preprint doi: https://doi.org/10.1101/2020.04.17.20069229; this version posted April 22, 2020. The copyright holder for this preprint (which was not certified by peer review) is the author/funder, who has granted medRxiv a license to display the preprint in perpetuity. It is made available under a CC-BY-NC-ND 4.0 International license.

In conclusion, we show that a high breast cancer PRS comes with a comparable risk profile to frameshift mutations in breast cancer susceptibility genes PALB2 and CHEK2 and that the PRS strongly modifies breast cancer risk in the mutation carriers. Even after the breast cancer diagnosis, the PRS was associated with breast cancer susceptibility by increasing the risk of contralateral breast cancer, and it considerably improved risk assessment among the patient's first-degree relatives. These results demonstrate opportunities for a more comprehensive way of assessing genetic risk in the general population, in breast cancer patients, and in unaffected family members of breast cancer patients. Optimization of these strategies in the clinical setting warrant further study. 
Figure 1. Geographic variation in genetic risk, compared to age-standardized breast cancer incidence. The PALB2 and CHEK2 maps show across different regions the proportion of women carrying at least one risk allele for the variants. The proportion of women with the breast cancer polygenic risk score (PRS) above the $90^{\text {th }}$ percentile in each region is estimated with respect to the PRS distribution of the whole country.

\section{Breast cancer incidence}

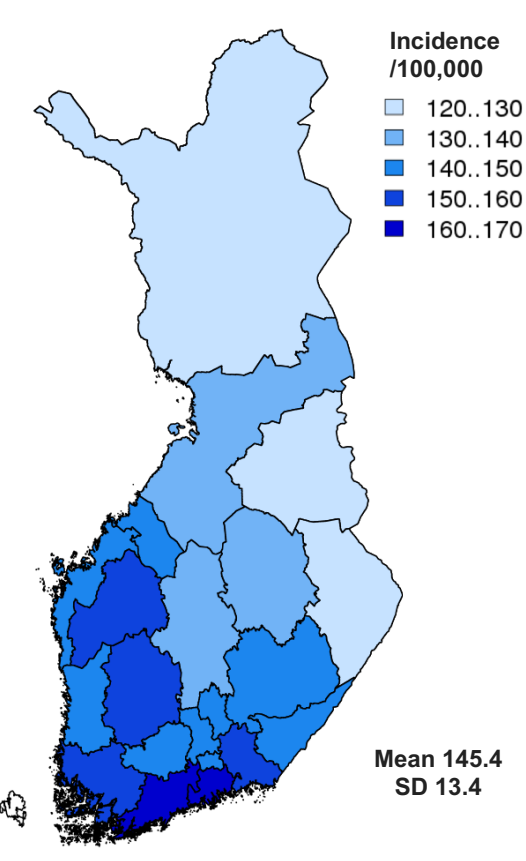

\section{Breast cancer PRS $>90 \%$}

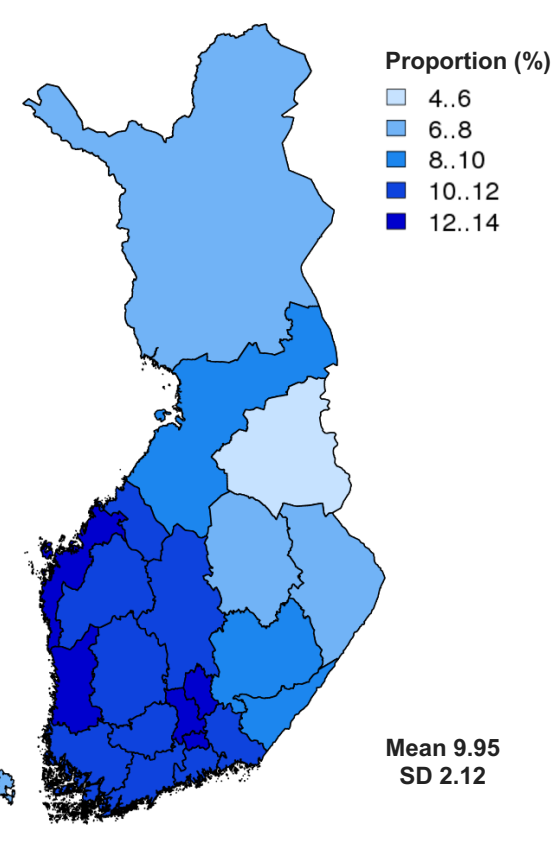

PALB2

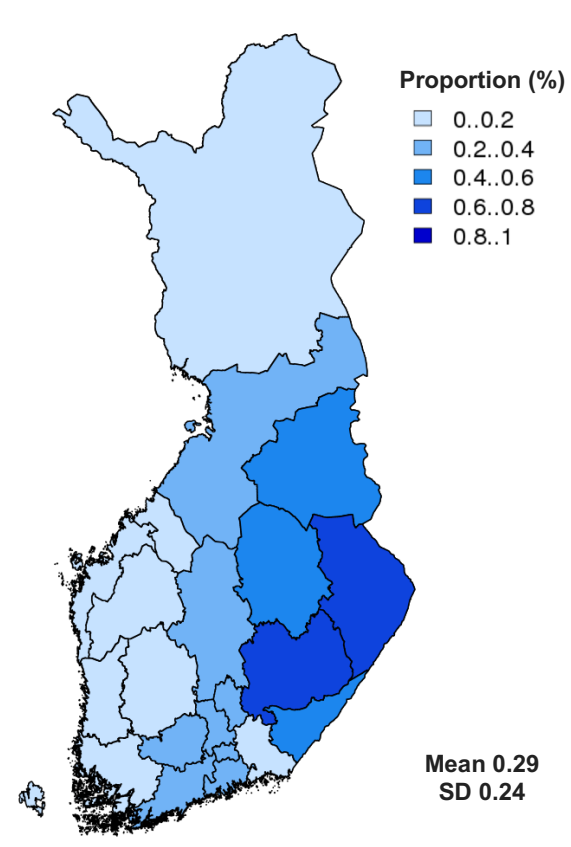

CHEK2

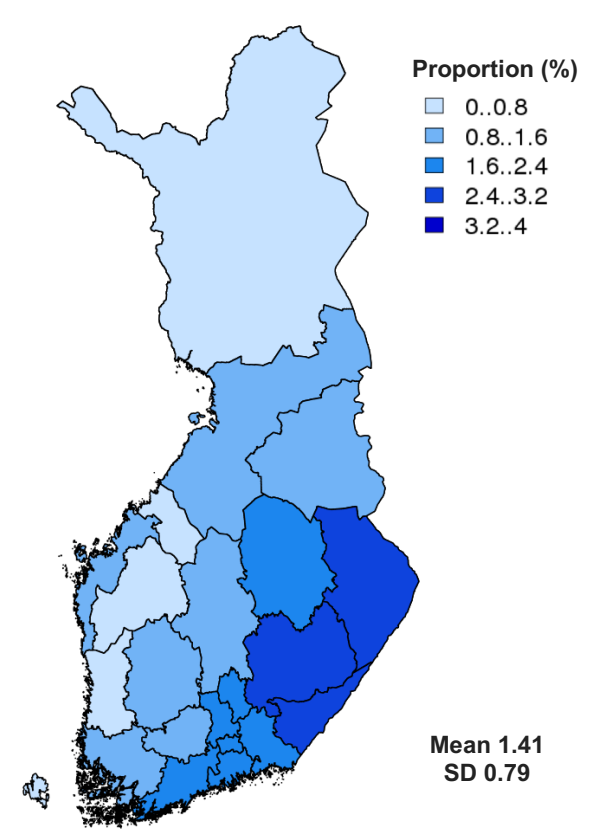

The areas represent region of birth obtained from Statistics Finland. The national breast cancer incidence in women was obtained from the Finnish Cancer Registry (publicly available at https://cancerregistry.fi/statistics/) with diagnosis C50 (International Classification of Diseases for Oncology, 3rd Edition, ICD-0-3). The incidence represents the mean of five-year age-standardized incidences (based on the 2014 Finnish population, calculated for each hospital district over 1998-2007). The mean and standard deviation were calculated over the different regions. Variants: rs180177102 (c.1592delT) for PALB2 and rs555607708 (c.1100deIC) for CHEK2. CHEK2 and polygenic risk score plots are based on 99,969 women, and PALB2 on 87,370 women. Colour contrasts were chosen approximately based on the standard deviation for each map. 
Table 1. Risk for breast cancer events in the population with different combinations of genetic risk assessment. The reference group for columns with the PRS is individuals with a PRS below the $80^{\text {th }}$ percentile. For columns with PALB2 or CHEK2, the reference group is the rest of the sample.

\begin{tabular}{|c|c|c|c|c|c|c|c|c|c|c|c|c|}
\hline & \multicolumn{2}{|c|}{ PRS 80-90\% } & \multicolumn{2}{|c|}{ PRS $>90 \%$} & \multicolumn{2}{|c|}{ CHEK2 } & \multicolumn{2}{|c|}{ CHEK2 and PRS 80-90\% } & \multicolumn{2}{|c|}{ CHEK2 and PRS >90\% } & \multicolumn{2}{|c|}{ PALB2 } \\
\hline Number of individuals & \multicolumn{2}{|c|}{9,997} & \multicolumn{2}{|c|}{9,997} & \multicolumn{2}{|c|}{1,543} & \multicolumn{2}{|l|}{160} & \multicolumn{2}{|l|}{166} & \multicolumn{2}{|l|}{263} \\
\hline Number of cases & \multicolumn{2}{|c|}{1,020} & \multicolumn{2}{|c|}{1,421} & \multicolumn{2}{|c|}{202} & \multicolumn{2}{|l|}{30} & \multicolumn{2}{|l|}{49} & \multicolumn{2}{|l|}{61} \\
\hline $\begin{array}{l}\text { Lifetime risk of breast } \\
\text { cancer, } \%(95 \% \mathrm{Cl})\end{array}$ & \multicolumn{2}{|c|}{$24.2(23.4-25.0)$} & \multicolumn{2}{|c|}{31.8 (30.9-32.7) } & \multicolumn{2}{|c|}{$31.8(29.5-34.1)$} & \multicolumn{2}{|c|}{$42.7(35.0-50.4)$} & \multicolumn{2}{|c|}{$59.0(51.5-66.5)$} & \multicolumn{2}{|c|}{$58.1(52.1-64.1)$} \\
\hline $\begin{array}{l}\text { Mean age at disease } \\
\text { onset in cases (SD) }\end{array}$ & \multicolumn{2}{|c|}{$58.4(11.5)$} & \multicolumn{2}{|c|}{$58.2(11.3)$} & \multicolumn{2}{|c|}{$57.3(12.1)$} & \multicolumn{2}{|c|}{$56.5(11.6)$} & \multicolumn{2}{|c|}{$53.6(12.8)$} & \multicolumn{2}{|c|}{$52.6(10.6)$} \\
\hline Outcome & HR (95\% Cl) & $\mathbf{p}$ & HR (95\% Cl) & $\mathbf{p}$ & HR (95\% Cl) & $\mathbf{p}$ & HR (95\% Cl) & $\mathbf{p}$ & HR (95\% Cl) & $\mathbf{p}$ & HR (95\% Cl) & $\mathbf{p}$ \\
\hline Breast cancer & $1.85(1.73-1.98)$ & $7.01 \times 10^{-70}$ & $2.58(2.42-2.73)$ & $1.41 \times 10^{-208}$ & $2.12(1.84-2.44)$ & $1.33 \times 10^{-25}$ & $3.81(2.66-5.46)$ & $3.26 \times 10^{-13}$ & $6.26(4.72-8.31)$ & $3.88 \times 10^{-37}$ & $4.80(3.72-6.18)$ & $1.08 \times 10^{-33}$ \\
\hline $\begin{array}{l}\text { Breast cancer } \\
\text { mortality }\end{array}$ & $1.57(1.13-2.18)$ & $7.25 \times 10^{-3}$ & $2.40(1.82-3.17)$ & $5.83 \times 10^{-10}$ & $1.90(0.97-3.70)$ & 0.06 & $7.88(2.50-24.8)$ & $4.24 \times 10^{-4}$ & $2.66(0.37-19.1)$ & 0.33 & $5.42(1.98-14.9)$ & $1.01 \times 10^{-3}$ \\
\hline $\begin{array}{l}\text { Non-localised breast } \\
\text { cancer at diagnosis }\end{array}$ & $1.90(1.67-2.17)$ & $2.65 \times 10^{-22}$ & $2.94(2.63-3.28)$ & $1.17 \times 10^{-81}$ & $2.56(2.01-3.28)$ & $6.20 \times 10^{-14}$ & $6.59(3.89-11.2)$ & $2.73 \times 10^{-12}$ & $8.09(4.93-13.3)$ & $1.23 \times 10^{-16}$ & $3.74(2.16-6.48)$ & $2.41 \times 10^{-6}$ \\
\hline Mastectomy & $1.78(1.58-2.00)$ & $1.35 \times 10^{-21}$ & $2.85(2.58-3.15)$ & $5.92 \times 10^{-96}$ & $2.15(1.70-2.71)$ & $1.31 \times 10^{-10}$ & $3.42(1.84-6.38)$ & $1.09 \times 10^{-4}$ & $8.14(5.38-12.3)$ & $2.93 \times 10^{-23}$ & 4.68 (3.09-7.08) & $2.80 \times 10^{-13}$ \\
\hline
\end{tabular}

PRS = polygenic risk score, $\mathrm{Cl}=$ confidence interval, $\mathrm{HR}=$ hazard ratio, $\mathrm{SD}=$ standard deviation. Variants: rs180177102 (c.1592delT) for PALB2 and rs555607708 (c.1100delC) for CHEK2. 
Figure 2. Adjusted survival curves showing how polygenic risk score (PRS) affects the breast cancer risk conferred by the PALB2 (top) and CHEK2 (bottom) frameshift mutations.

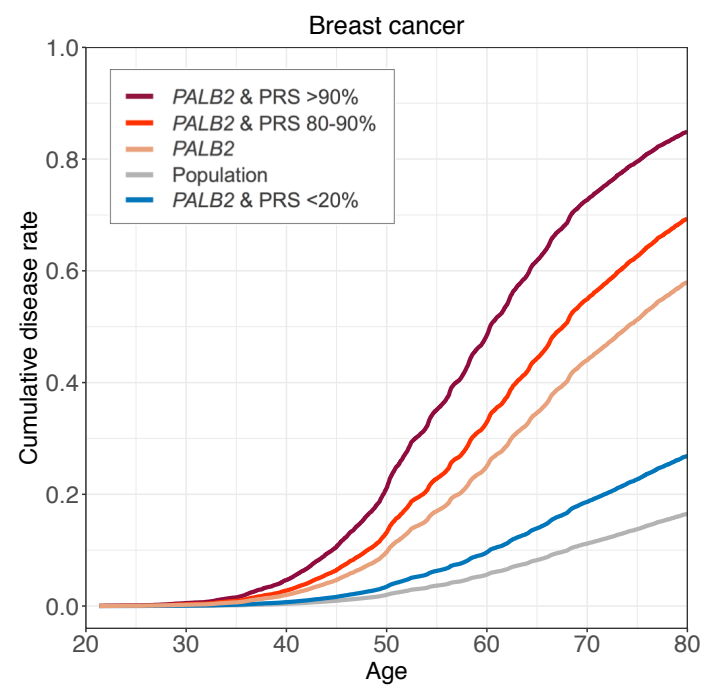

\begin{tabular}{lccccc} 
& HR $(95 \% \mathrm{Cl})$ & $\mathbf{p}$ & Lifetime risk, \% $(95 \% \mathrm{Cl})$ & Cases & Controls \\
\hline PALB2 \& PRS >90\% & $12.00(5.97-24.1)$ & $2.83 \times 10^{-12}$ & $84.9(69.9-99.9)$ & 8 & 14 \\
PALB2 \& PRS >80\% & $7.08(3.91-12.8)$ & $1.05 \times 10^{-10}$ & $69.3(51.9-86.7)$ & 11 & 16 \\
PALB2 & $5.07(3.68-6.99)$ & $3.92 \times 10^{-23}$ & $58.0(50.4-65.6)$ & 38 & 125 \\
PRS 20-80\% & $1.00($ reference) & - & $16.5(16.2-16.8)$ & 3,341 & 49,021 \\
PALB2 \& PRS $<20 \%$ & $1.75(0.66-4.68)$ & 0.26 & $26.9(14.7-39.1)$ & 4 & 47
\end{tabular}

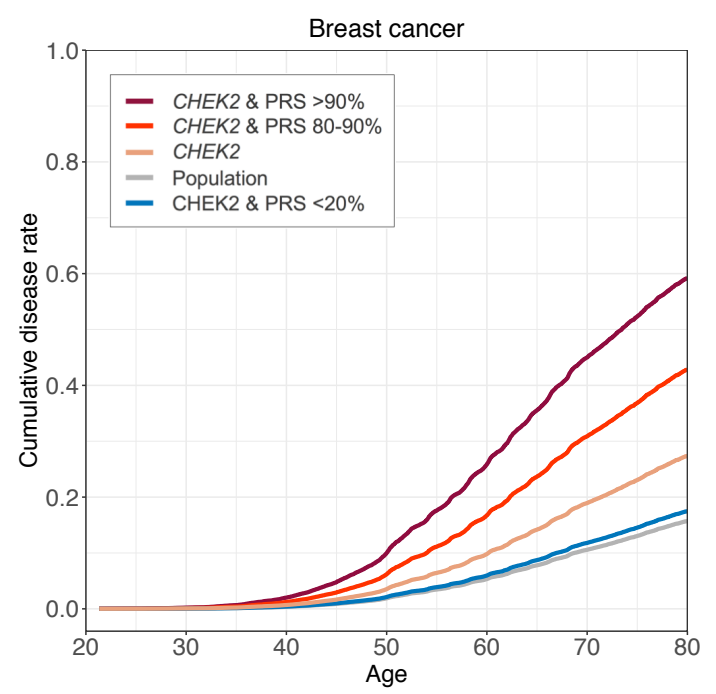

\begin{tabular}{lccccc} 
& HR $(95 \% \mathrm{Cl})$ & $\mathbf{p}$ & Lifetime risk, \% $(95 \% \mathrm{Cl})$ & Cases & Controls \\
\hline CHEK2 \& PRS $>90 \%$ & $5.58(4.20-7.40)$ & $1.01 \times 10^{-32}$ & $59.2(51.7-66.7)$ & 49 & 117 \\
CHEK2 \& PRS $>80 \%$ & $3.38(2.36-4.84)$ & $3.43 \times 10^{-11}$ & $42.8(35.1-50.5)$ & 30 & 130 \\
CHEK2 & $1.89(1.56-2.30)$ & $1.31 \times 10^{-10}$ & $27.4(24.5-30.3)$ & 105 & 833 \\
PRS 20-80\% & $1.00($ reference) & - & $15.7(15.4-16.0)$ & 3,699 & 55,344 \\
CHEK2 \& PRS <20\% & $1.13(0.71-1.79)$ & 0.62 & $17.5(13.0-22.0)$ & 18 & 261
\end{tabular}

Population level defined as women with PRS between the $20^{\text {th }}$ and $80^{\text {th }}$ percentiles. Variants: rs 180177102 (c.1592delT) for PALB2 and rs555607708 (c.1100delC) for CHEK2. PALB2 analysis was done in 87,370 women and CHEK2 analysis in 99,969 women. 
medRxiv preprint doi: https://doi.org/10.1101/2020.04.17.20069229; this version posted April 22, 2020. The copyright holder for this preprint (which was not certified by peer review) is the author/funder, who has granted medRxiv a license to display the preprint in perpetuity. It is made available under a CC-BY-NC-ND 4.0 International license .

Table 2. Impact of high polygenic risk score (PRS) on the risk of contralateral breast cancer and breast cancer mortality in cases.

$\operatorname{HR}(95 \% \mathrm{Cl})$

p

Risk of contralateral breast cancer in cases, $\mathrm{n}=\mathbf{2 3 5}$

PRS $>90 \%$, unadjusted model

$1.66(1.24-2.22)$

0.0007

PRS $>90 \%$, adjusted model

$1.67(1.25-2.24)$

0.0006

Age at diagnosis

$1.00(0.98-1.01)$

0.72

Non-localized breast cancer at diagnosis

$0.89(0.66-1.19)$

0.42

Breast-conserving surgery at baseline

$1.23(0.87-1.74)$

0.24

Mastectomy at baseline

$1.21(0.84-1.75)$

0.30

\section{Breast cancer mortality in cases, $\mathbf{n}=291$}

PRS $>90 \%$, unadjusted model

PRS $>90 \%$, adjusted model

Age at diagnosis

Non-localized breast cancer at diagnosis

Breast-conserving surgery at baseline

Mastectomy at baseline
$0.93(0.69-1.24)$

0.61

0.89 (0.66-1.20)

0.44

1.05 (1.03-1.06)

$2.80 \times 10^{-14}$

2.60 (2.05-3.30)

$4.11 \times 10^{-15}$

$0.52(0.36-0.74)$

0.0003

$1.23(0.92-1.65)$

0.17

$\mathrm{HR}=$ hazard ratio, $\mathrm{Cl}=$ confidence interval. The reference group for the PRS is $<80 \%$, and the PRS categories are based on all 99,969 women. Analysis based on 5,979 breast cancer cases, after excluding 40 individuals with follow-up less than one year and cases without detailed Cancer Registry data (mostly newly diagnosed cases; see Methods for details). Controls are breast cancer cases without the event of interest. Mastectomies and breast-conserving surgery at baseline follow the definitions described in the Methods, but were here restricted to procedures \pm 6 months from the first breast cancer diagnosis. 
Figure 3. Impact of polygenic risk score (PRS) in estimating the breast cancer risk of women with a first-degree relative diagnosed with breast cancer.
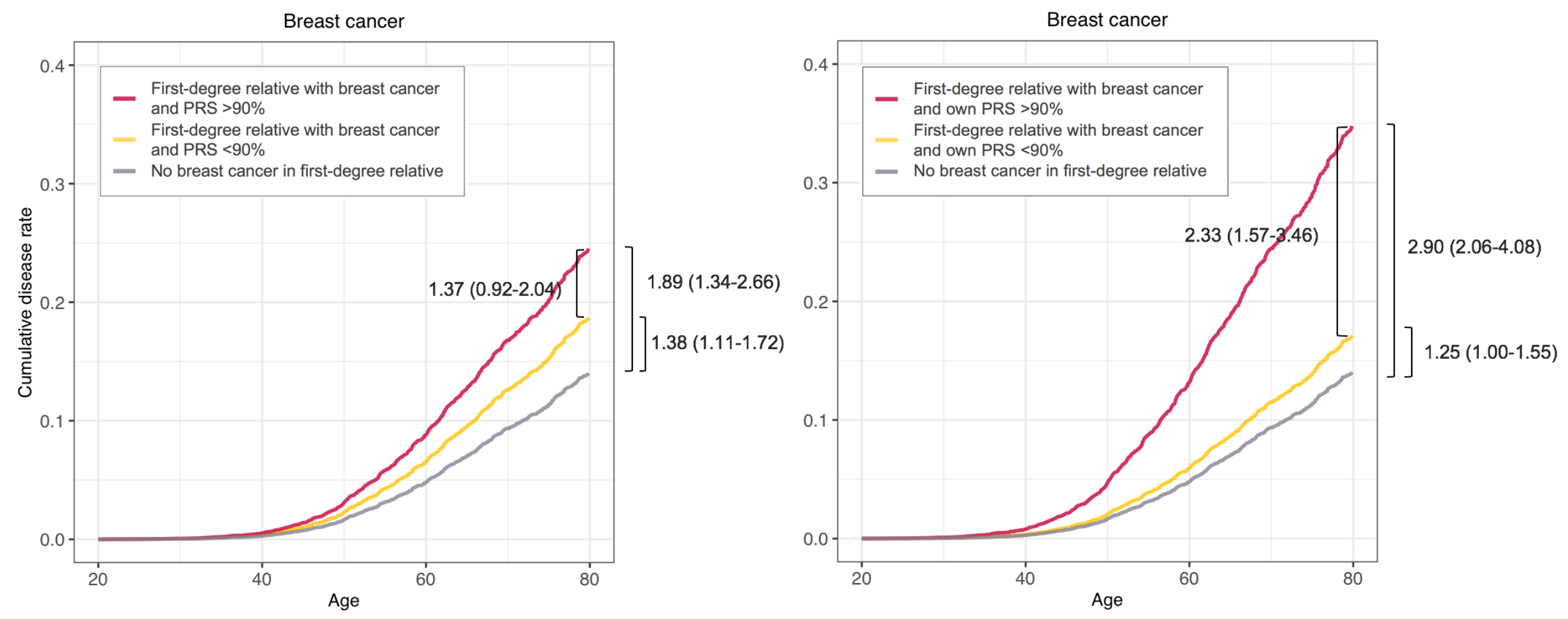

Adjusted survival curves based on Cox proportional hazards models. Risk estimated in 9,702 parent-offspring pairs and 9,598 full sibling-pairs. The pairs of first-degree relatives were inferred with KING by a kinship coefficient ranging between 0.177 and 0.354 (inference based on $57 \mathrm{~K}$ variants). Case and control counts underlying the plots were following: left plot 34 and 207 (red), 87 and 827 (yellow), 1,028 and 17,117 (gray); right plot 35 and 137 (red), 86 and 897 (yellow), 1,028 and 17,117 (gray). 
medRxiv preprint doi: https://doi.org/10.1101/2020.04.17.20069229; this version posted April 22, 2020. The copyright holder for this preprint (which was not certified by peer review) is the author/funder, who has granted medRxiv a license to display the preprint in perpetuity. It is made available under a CC-BY-NC-ND 4.0 International license.

\section{REFERENCES}

1. $\quad$ Bray F, Ferlay J, Soerjomataram I, Siegel RL, Torre LA, Jemal A. Global cancer statistics 2018: GLOBOCAN estimates of incidence and mortality worldwide for 36 cancers in 185 countries. Ca-a Cancer Journal for Clinicians. 2018;68:394-424

2. Economopoulou P, Dimitriadis G, Psyrri A. Beyond BRCA: New hereditary breast cancer susceptibility genes. Cancer Treat. Rev. 2015;41:1-8

3. Vehmanen P, Friedman LS, Eerola H, McClure M, Ward B, Sarantaus L, et al. Low proportion of BRCA1 and BRCA2 mutations in Finnish breast cancer families: Evidence for additional susceptibility genes. Hum. Mol. Genet. 1997;6:2309-2315

4. Ducy M, Sesma-Sanz L, Guitton-Sert L, Lashgari A, Gao Y, Brahiti N, et al. The tumor suppressor PALB2: Inside out. Trends Biochem. Sci. 2019;44:226-240

5. Nevanlinna H, Bartek J. The CHEK2 gene and inherited breast cancer susceptibility. Oncogene. 2006;25:5912-5919

6. Michailidou K, Lindstrom S, Dennis J, Beesley J, Hui S, Kar S, et al. Association analysis identifies 65 new breast cancer risk loci. Nature. 2017;551:92-94

7. Mavaddat N, Michailidou K, Dennis J, Lush M, Fachal L, Lee A, et al. Polygenic risk scores for prediction of breast cancer and breast cancer subtypes. Am. J. Hum. Genet. 2019;104:21-34

8. Chatterjee N, Shi J, Garcia-Closas M. Developing and evaluating polygenic risk prediction models for stratified disease prevention. Nat. Rev. Genet. 2016;17:392-406

9. Lee A, Mavaddat N, Wilcox AN, Cunningham AP, Carver T, Hartley S, et al. BOADICEA: A comprehensive breast cancer risk prediction model incorporating genetic and nongenetic risk factors. Genet. Med. 2019;21:1708-1718

10. Leinonen MK, Miettinen J, Heikkinen S, Pitkaniemi J, Malila N. Quality measures of the populationbased Finnish Cancer Registry indicate sound data quality for solid malignant tumours. Eur. J. Cancer. 2017;77:31-39

11. Loh PR, Danecek P, Palamara PF, Fuchsberger C, Reshef YA, Finucane HK, et al. Reference-based phasing using the Haplotype Reference Consortium panel. Nat. Genet. 2016;48:1443-1448

12. Browning BL, Browning SR. Genotype imputation with millions of reference samples. Am. J. Hum. Genet. 2016;98:116-126

13. Mars N, Koskela JT, Ripatti P, Kiiskinen TTJ, Havulinna AS, Lindbohm JV, et al. Polygenic and clinical risk scores and their impact on age at onset and prediction of cardiometabolic diseases and common cancers. Nat. Med. 2020

14. Vilhjalmsson BJ, Yang J, Finucane HK, Gusev A, Lindstrom S, Ripke S, et al. Modeling linkage disequilibrium increases accuracy of polygenic risk scores. Am. J. Hum. Genet. 2015;97:576-592

15. Nice clinical guidelines, no. 164. Familial breast cancer: Classification and care of people at risk of familial breast cancer and management of breast cancer and related risks in people with a family history of breast cancer. 2013

16. Kerminen S, Martin AR, Koskela J, Ruotsalainen SE, Havulinna AS, Surakka I, et al. Geographic variation and bias in the polygenic scores of complex diseases and traits in finland. Am. J. Hum. Genet. 2019;104:1169-1181

17. Manichaikul A, Mychaleckyj JC, Rich SS, Daly K, Sale M, Chen WM. Robust relationship inference in genome-wide association studies. Bioinformatics. 2010;26:2867-2873

18. Zhou W, Nielsen JB, Fritsche LG, Dey R, Gabrielsen ME, Wolford BN, et al. Efficiently controlling for case-control imbalance and sample relatedness in large-scale genetic association studies. Nat.

Genet. 2018;50:1335-1341 
medRxiv preprint doi: https://doi.org/10.1101/2020.04.17.20069229; this version posted April 22, 2020. The copyright holder for this preprint (which was not certified by peer review) is the author/funder, who has granted medRxiv a license to display the preprint in perpetuity. It is made available under a CC-BY-NC-ND 4.0 International license.

19. May S, Hosmer DW. A simplified method of calculating an overall goodness-of-fit test for the cox proportional hazards model. Lifetime Data Anal. 1998;4:109-120

20. Karczewski KJ, Francioli LC, Tiao G, Cummings BB, Alföldi J, Wang Q, et al. Variation across 141,456 human exomes and genomes reveals the spectrum of loss-of-function intolerance across human protein-coding genes. bioRxiv. 2019:531210

21. Khera AV, Chaffin M, Aragam KG, Haas ME, Roselli C, Choi SH, et al. Genome-wide polygenic scores for common diseases identify individuals with risk equivalent to monogenic mutations. Nat. Genet. 2018;50:1219-1224

22. Reiner AS, Sisti J, John EM, Lynch CF, Brooks JD, Mellemkjaer L, et al. Breast cancer family history and contralateral breast cancer risk in young women: An update from the women's environmental cancer and radiation epidemiology study. J. Clin. Oncol. 2018;36:1513-1520

23. Narod SA, Kharazmi E, Fallah M, Sundquist K, Hemminki K. The risk of contralateral breast cancer in daughters of women with and without breast cancer. Clin. Genet. 2016;89:332-335

24. Antoniou AC, Casadei S, Heikkinen T, Barrowdale D, Pylkäs K, Roberts J, et al. Breast-cancer risk in families with mutations in PALB2. N. Engl. J. Med. 2014;371:497-506

25. Antoniou AC, Pharoah PD, McMullan G, Day NE, Stratton MR, Peto J, et al. A comprehensive model for familial breast cancer incorporating BRCA1, BRCA2 and other genes. Br. J. Cancer. 2002;86:76-83

26. Kuchenbaecker KB, McGuffog L, Barrowdale D, Lee A, Soucy P, Dennis J, et al. Evaluation of polygenic risk scores for breast and ovarian cancer risk prediction in BRCA1 and BRCA2 mutation carriers. J. Natl. Cancer Inst. 2017;109

27. Tung N, Domchek SM, Stadler Z, Nathanson KL, Couch F, Garber JE, et al. Counselling framework for moderate-penetrance cancer-susceptibility mutations. Nat Rev Clin Oncol. 2016;13:581-588

28. Kerminen S, Havulinna AS, Hellenthal G, Martin AR, Sarin AP, Perola M, et al. Fine-scale genetic structure in finland. G3 (Bethesda). 2017;7:3459-3468 
medRxiv preprint doi: https://doi.org/10.1101/2020.04.17.20069229; this version posted April 22, 2020. The copyright holder for this preprint (which was not certified by peer review) is the author/funder, who has granted medRxiv a license to display the preprint in perpetuity. It is made available under a CC-BY-NC-ND 4.0 International license.

Acknowledgements We would like to thank Sari Kivikko, Huei-Yi Shen and Ulla Tuomainen for management assistance. Following biobanks are acknowledged for collecting the FinnGen project samples: Auria Biobank (https://www.auria.fi/biopankki), THL Biobank (https://thl.fi/fi/web/thl-biopankki), Helsinki Biobank (https://www.terveyskyla.fi/helsinginbiopankki), Biobank Borealis of Northern Finland (https://www.oulu.fi/university/node/38474), Finnish Clinical Biobank Tampere (https://www.tays.fi/enUS/Research_and_development/Finnish_Clinical_Biobank_Tampere), Biobank of Eastern Finland (https://itasuomenbiopankki.fi), Central Finland Biobank (https://www.ksshp.fi/fi-Fl/Potilaalle/Biopankki), Finnish Red Cross Blood Service Biobank (https://www.veripalvelu.fi/verenluovutus/biopankkitoiminta) and Terveystalo Biobank (https://www.terveystalo.com/fi/Yritystietoa/Terveystalo-Biopankki/Biopankki/). All Finnish Biobanks are members of BBMRI.fi infrastructure (www.bbmri.fi). We also thank study participants for their generous participation at THL Biobank and the National FINRISK study. The content is solely the responsibility of the authors and does not necessarily represent the official views of the National Institutes of Health.

The FinnGen project is funded by two grants from Business Finland (HUS 4685/31/2016 and UH 4386/31/2016) and by eleven industry partners (AbbVie Inc, AstraZeneca UK Ltd, Biogen MA Inc, Celgene Corporation, Celgene International II Sàrl, Genentech Inc, Merck Sharp \& Dohme Corp, Pfizer Inc., GlaxoSmithKline, Sanofi, Maze Therapeutics Inc., Janssen Biotech Inc).

This work was supported by the Sigrid Jusélius Foundation [to S.R., A.P., M.P., and H.J.]; University of Helsinki HiLIFE Fellow grants 2017-2020 [to S.R.]; Academy of Finland Center of Excellence in Complex Disease Genetics [grant number 312062 to S.R., 312074 to A.P., 312075 to M.D; 312073 to J.K.; 312076 to M.P.]; Academy of Finland [grant number 285380 to S.R, 128650 to A.P., 308248 to J.K., 288509 to M.P., 218068 and 131449 to H.J.]; The Finnish Innovation Fund Tekes [grant number 2273/31/2017 to E.W.]; Foundation and the Horizon 2020 Research and Innovation Programme [grant number 667301 (COSYN) to A.P]; Cancer Foundation Finland sr [to T.M.]; Cancer Society of Finland [to H.J.]; Jane and Aatos Erkko Foundation [to H.J.]. The funders had no role in study design, data collection and analysis, decision to publish, or preparation of the manuscript.

Conflicts of interests A.P. is a member of the Pfizer Genetics Scientific Advisory Panel. H.J. has a coappointment at Orion Pharma, has received fees from Neutron Therapeutics, and owns stocks of Orion Pharma and Sartar Therapeutics.

Data availability The FinnGen data may be accessed through Finnish Biobanks' FinnBB portal (www.finbb.fi) and THL Biobank data through THL Biobank (https://thl.fi/en/web/thl-biobank). 